\title{
Improvement of Thermoelectric Properties through Reduction of Thermal Conductivity by Nanoparticle Addition and Stoichiometric Change to $\mathrm{Mg}_{2} \mathrm{Si}$
}

\author{
W. Tanner Yorgason \\ Arden Barnes \\ N. A. Roberts
}

Mechanical and Aerospace Engineering

Utah State University

(April 13 ${ }^{\text {th }}$ 2017, Utah State University, Student Research Symposium) 


\section{Motivation}

Estimated U.S. Energy Use in 2013: 97.4 Quads

Net Electricity
Imports

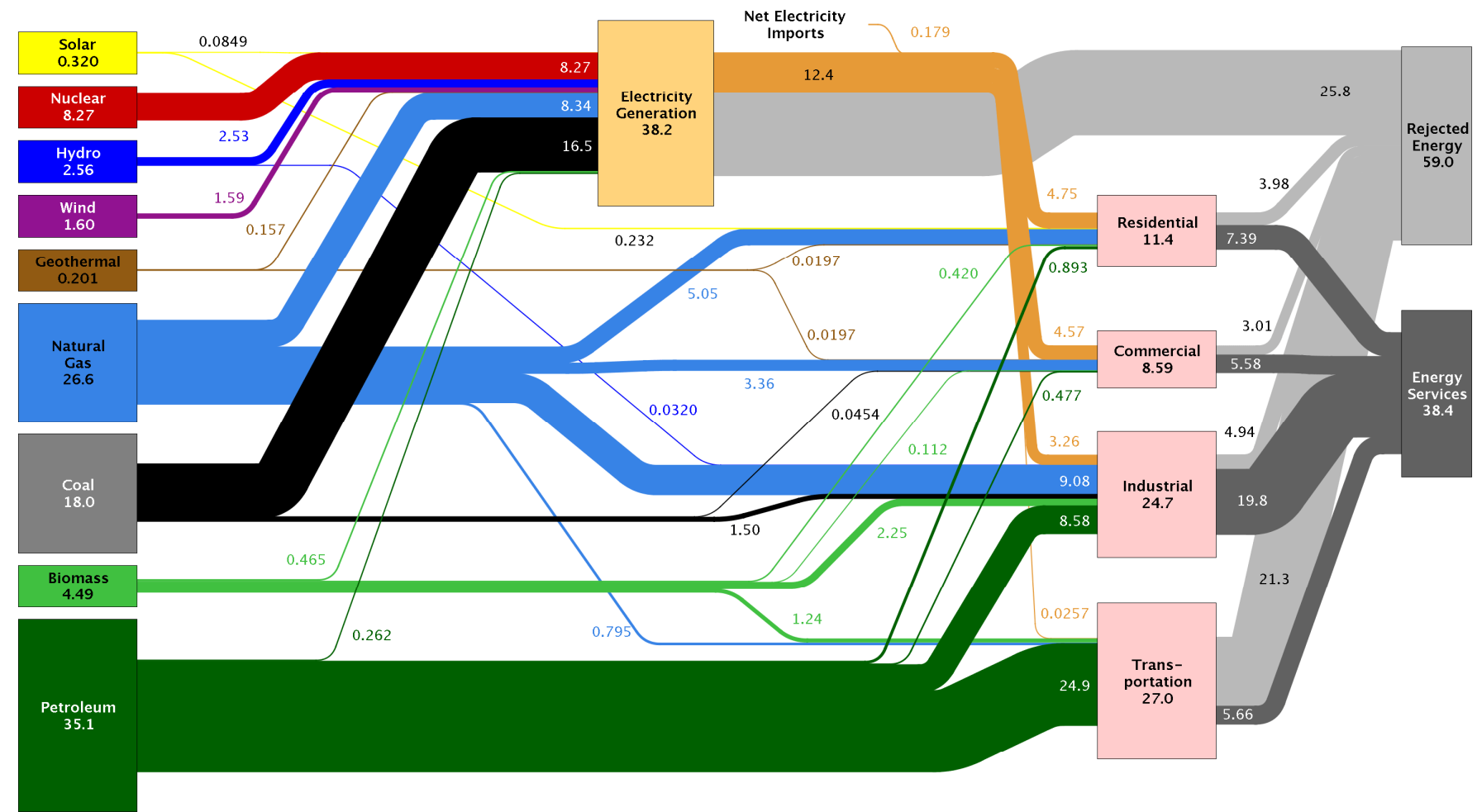

Source: LNL 2014. Data is based on DOE/EIA-0035(2014-03), March, 2014 . If this information or a reproduction of it is used, credit must be given to the Lawrence Livermore National Laboratory
and the Department of Energy, under whose auspices the work was performed. Distributed electricicty represents only retail electricity sales and does not include self-generation. ElA reports

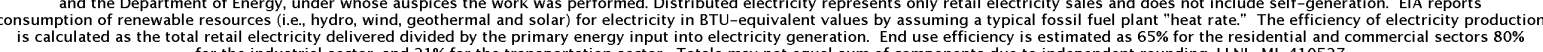

https://flowcharts.IInl.gov/archive.html 


\section{Motivation}

\section{MATERIALS}

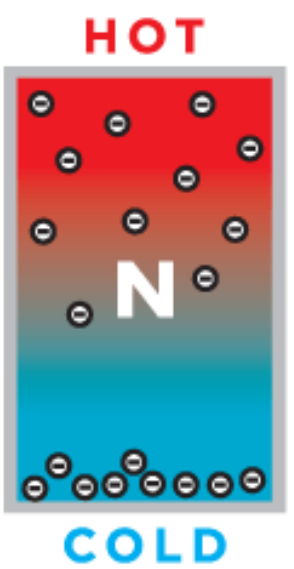

0
$\frac{1}{u}$
$\frac{u}{\alpha}$
u
u

MODULE

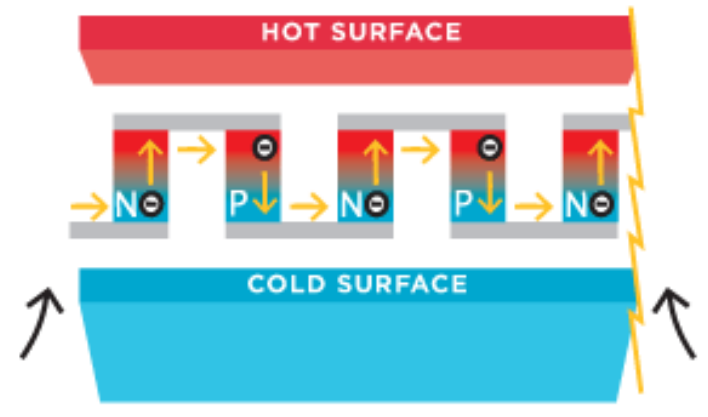

SYSTEM

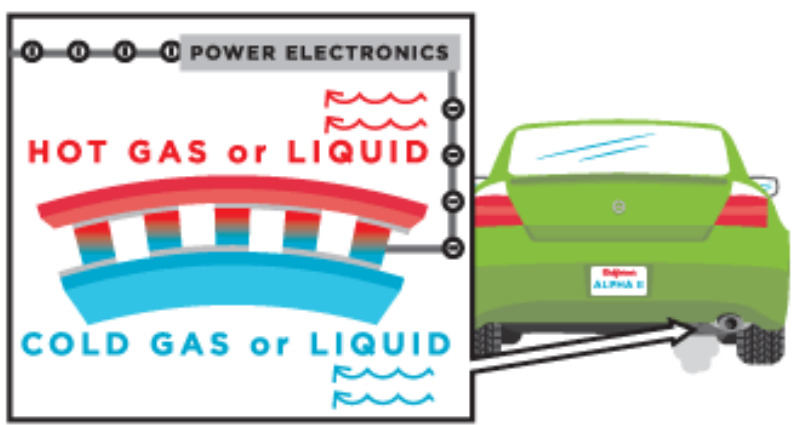

https://www.alphabetenergy.com/how-thermoelectrics-work/ 


\section{Motivation}

Figure of Merit $(Z T)$ is a measure of the thermoelectric material's efficiency in converting thermal energy to electrical current.

It is defined by the following equation: $\quad Z T=S^{2} \frac{\sigma T}{k}$


Temperature $(\mathrm{K})$

Temperature $(\mathrm{K})$

Rull-Bravo, RSC Advances, 2015 


\section{Motivation}

Why Use $\mathrm{Mg}_{2} \mathrm{Si}$ ?

- Mg is earth abundant in Utah and much of the US

- $\mathrm{Mg}_{2} \mathrm{Si}$ is a relatively simple compound when compared to the other thermoelectrics

- $\mathrm{Mg}$ is inexpensive, resulting in the production of $\mathrm{Mg}_{2} \mathrm{Si}$ being less expensive
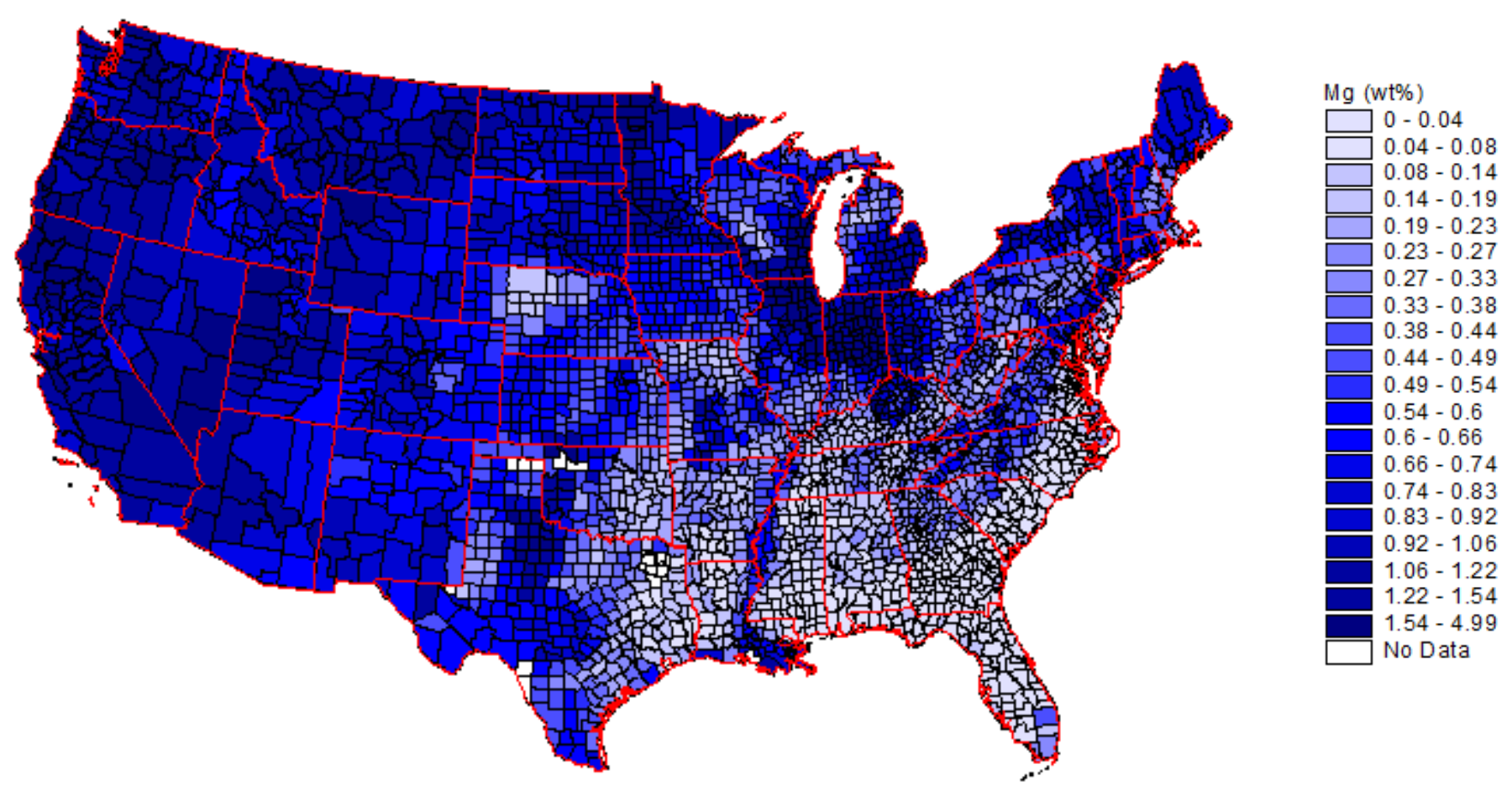

https://mrdata.usgs.gov/geochem/doc/averages/mg/usa.html 


\section{Methodology}

Molecular Dynamics

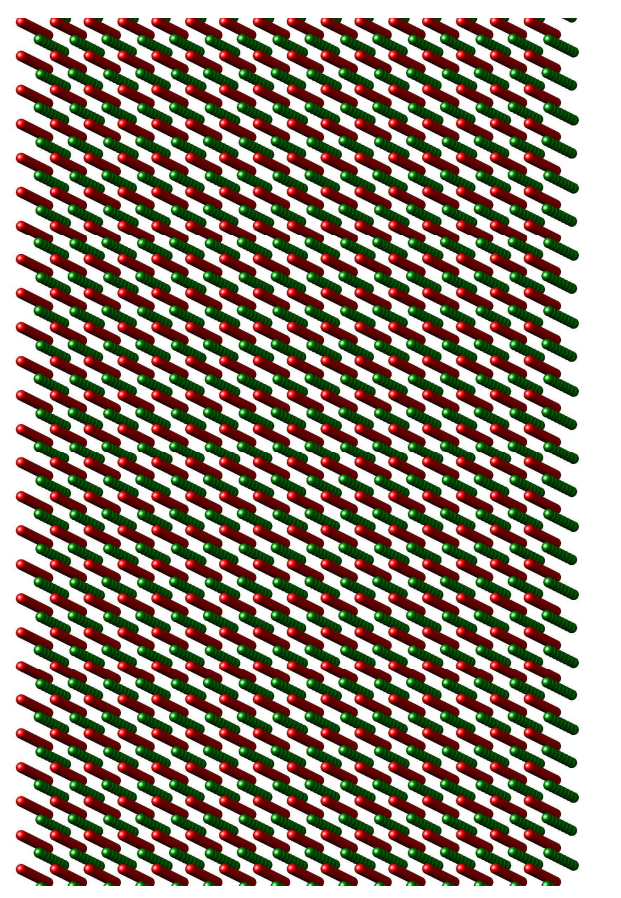

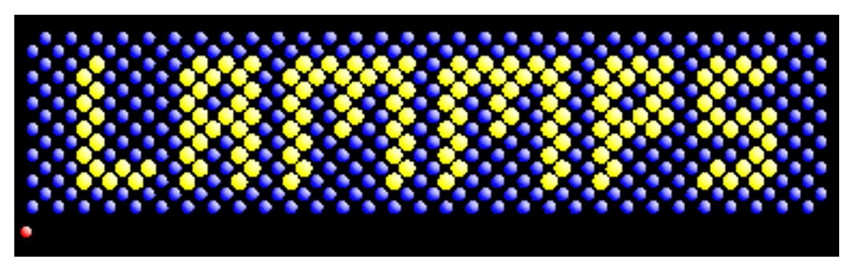

(Large-scale Atomic/Molecular Massively Parallel Simulator)

$$
Z T=S^{2} \frac{\sigma T}{k} k=k_{p}+k_{e}
$$

LAMMPS can only calculate $k_{p}$, which makes the follow up of experimental research to measure $Z T$ critical

http://lammps.sandia.gov/\#nogo 


\section{Experimental Setup}

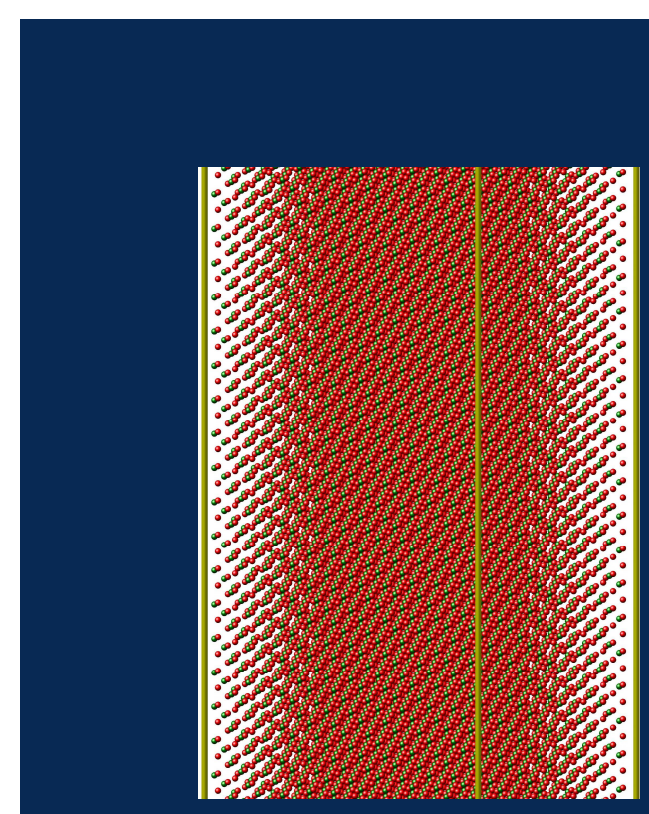

Pure $\mathrm{Mg}_{2} \mathrm{Si}$

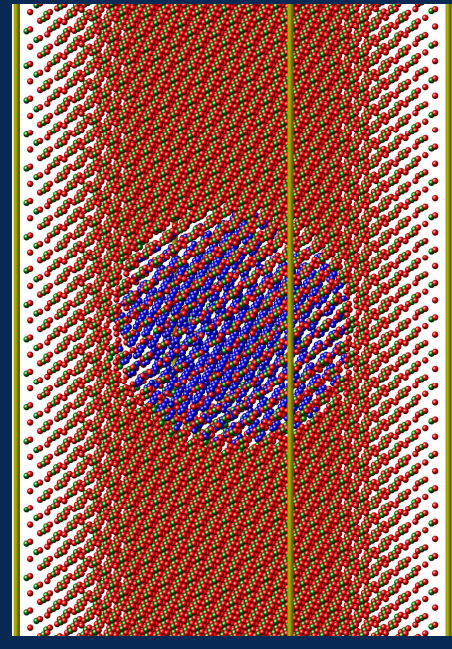

Pure $\mathrm{Mg}_{2} \mathrm{Si}$ with Si

NP

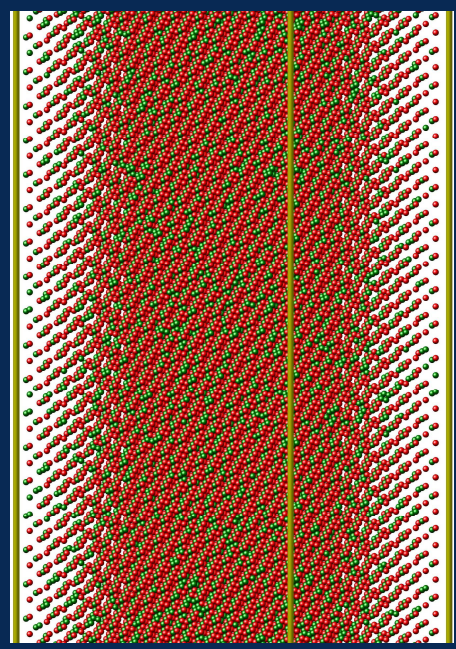

$\mathrm{Mg}_{x} \mathrm{Si}_{x}$ with $41.37 \%$ Si (matching the Si \% of the sample with 8 Si NPs)

落

UtahStateUniversity 


\section{Experimental Setup}

\begin{tabular}{|c|c|c|c|}
\hline Nanostructure & $300 \mathrm{~K}\left(\mathrm{Wm}^{-1} \mathrm{~K}^{-1}\right)$ & $600 \mathrm{~K}\left(\mathrm{Wm}^{-1} \mathrm{~K}^{-1}\right)$ & $900 \mathrm{~K}\left(\mathrm{Wm}^{-1} \mathrm{~K}^{-1}\right)$ \\
\hline Pure $\mathrm{Mg}_{2} \mathrm{Si}$ & $k_{p}=?$ & $k_{p}=?$ & $k_{p}=?$ \\
\hline $\mathrm{Mg}_{2} \mathrm{Si}$ with 1 Si NP & $k_{p}=?$ & $k_{p}=?$ & $k_{p}=?$ \\
\hline $\mathrm{Mg}_{2} \mathrm{Si}$ with $2 \mathrm{Si} \mathrm{NP}$ & $k_{p}=?$ & $k_{p}=?$ & $k_{p}=?$ \\
\hline $\mathrm{Mg}_{2} \mathrm{Si}$ with $4 \mathrm{Si} N \mathrm{P}$ & $k_{p}=?$ & $k_{p}=?$ & $k_{p}=?$ \\
\hline $\mathrm{Mg}_{2} \mathrm{Si}$ with $8 \mathrm{Si} \mathrm{NP}$ & $k_{p}=?$ & $k_{p}=?$ & $k_{p}=?$ \\
\hline $\mathrm{Mg}_{2} \mathrm{Si}$ with $16 \mathrm{Si} N \mathrm{P}$ & $k_{p}=?$ & $k_{p}=?$ & $k_{p}=?$ \\
\hline $\mathrm{Mg}_{x} \mathrm{Si}_{x} 34.29 \% \mathrm{Si}$ (matching stoichiometry of $\mathrm{Mg}_{2} \mathrm{Si}$ with $1 \mathrm{Si} N \mathrm{NP}$ ) & $k_{p}=?$ & $k_{p}=?$ & $k_{p}=?$ \\
\hline $\mathrm{Mg}_{x} \mathrm{Si}_{x} 35.32 \% \mathrm{Si}$ (matching stoichiometry of $\mathrm{Mg}_{2} \mathrm{Si}$ with 2 Si NP) & $k_{p}=?$ & $k_{p}=?$ & $k_{p}=?$ \\
\hline $\mathrm{Mg}_{x} \mathrm{Si}_{\mathrm{x}} 37.29 \% \mathrm{Si}$ (matching stoichiometry of $\mathrm{Mg}_{2} \mathrm{Si}$ with $4 \mathrm{Si} \mathrm{NP}$ ) & $k_{p}=?$ & $k_{p}=?$ & $k_{p}=?$ \\
\hline $\mathrm{Mg}_{x} \mathrm{Si}_{x} 41.37 \% \mathrm{Si}$ (matching stoichiometry of $\mathrm{Mg}_{2} \mathrm{Si}$ with $8 \mathrm{Si} \mathrm{NP}$ ) & $k_{p}=?$ & $k_{p}=?$ & $k_{p}=?$ \\
\hline $\mathrm{Mg}_{x} \mathrm{Si}_{x} 49.55 \% \mathrm{Si}$ (matching stoichiometry of $\mathrm{Mg}_{2} \mathrm{Si}$ with $16 \mathrm{Si} \mathrm{NP}$ ) & $k_{p}=?$ & $k_{p}=?$ & $k_{p}=?$ \\
\hline
\end{tabular}




\section{Methodology}

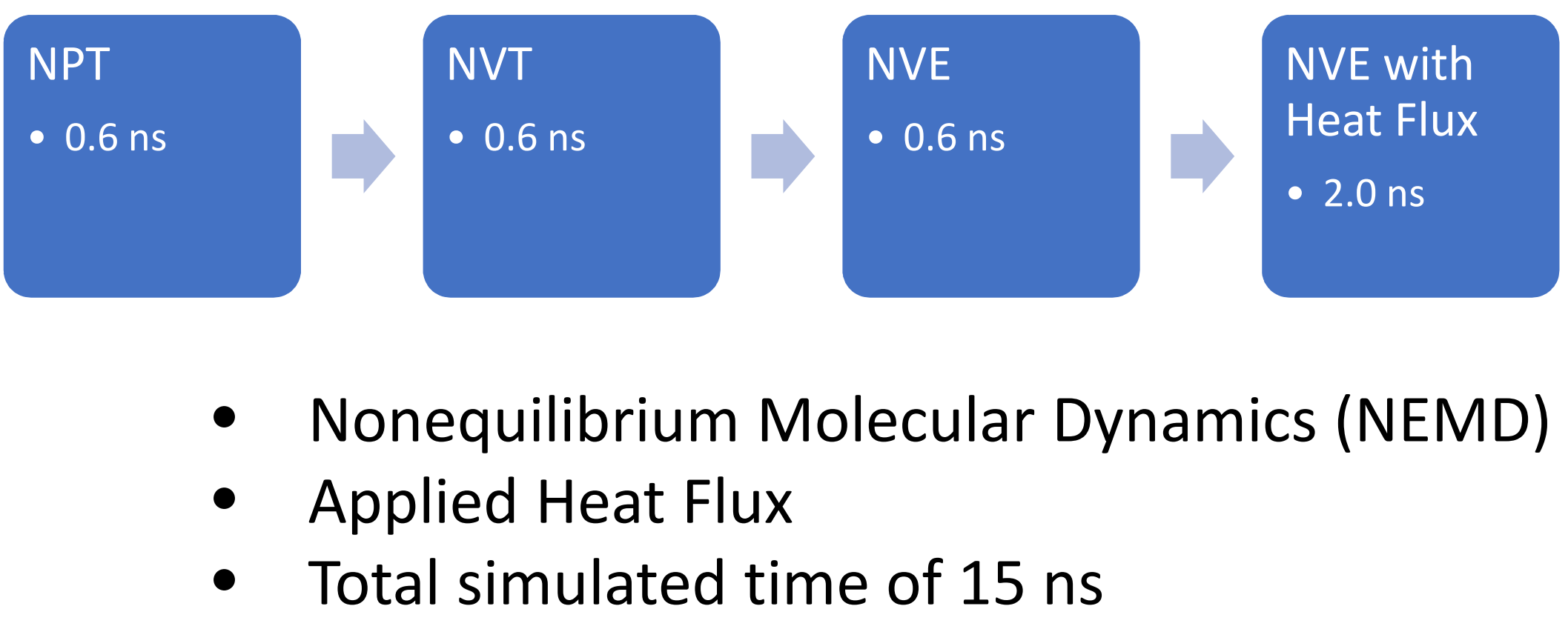

NVE with

Heat Flux

Recording

- $11.2 \mathrm{~ns}$

- Nonequilibrium Molecular Dynamics (NEMD)

- Applied Heat Flux

- Total simulated time of 15 ns 


\section{Methodology}

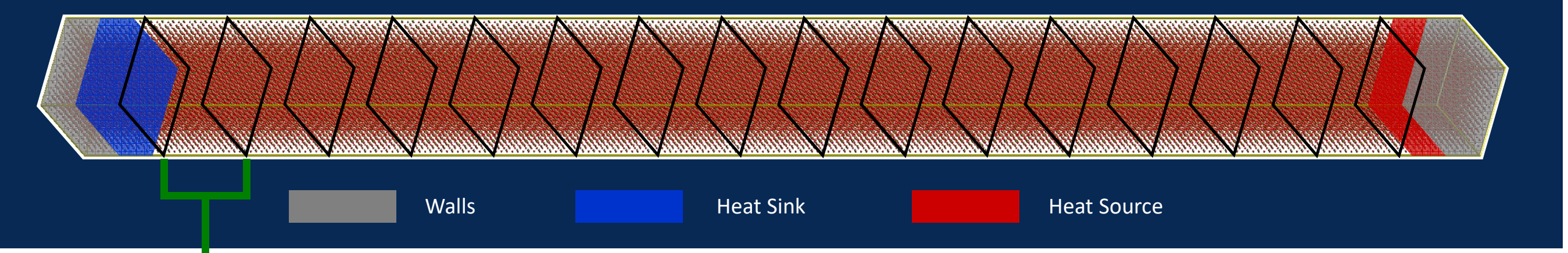

Chunk

\section{Fourier's Law}

$$
q=-k \frac{\Delta T}{\Delta x} \quad \Rightarrow \quad k=-q \frac{\Delta x}{\Delta T}
$$




\section{Uncertainty Calculations}

- Simulations were run at the 3 different equilibration temperatures as previously described, except that no heat flux was applied (we assumed stoichiometry did not significantly

$$
\text { NPT }
$$

- $0.6 \mathrm{~ns}$
NVT

- $0.6 \mathrm{~ns}$
NVE

- $13.8 \mathrm{~ns}$ affect the uncertainty in temperature)

- The temperatures for each chunk were then averaged all together

- The absolute value of the difference between this value and the target equilibration temperature was taken as our uncertainty in temperature

\begin{tabular}{|c|c|}
\hline $\begin{array}{c}\text { Equilibration } \\
\text { Temperature (K) }\end{array}$ & Uncertainty (K) \\
\hline 300 & 0.774 \\
\hline 600 & 0.721 \\
\hline 900 & 0.96 \\
\hline
\end{tabular}

- This value was then added to and subtracted from the $\Delta T$ in Fourier's Law to obtain the minimum and maximum $k_{p}$ values, and therefore their associated $k_{p}$ uncertainties 


\section{Results - Pure $\mathrm{Mg}_{2} \mathrm{Si}$}

\begin{tabular}{|c|c|}
\hline Work & $k_{p}$ of Pure $\mathrm{Mg}_{2} \mathrm{Si}$ at $300 \mathrm{~K}\left(\mathrm{Wm}^{-1} \mathrm{~K}^{-1}\right)$ \\
\hline LaBotz & 7.8 \\
\hline This Work & $8.454 \pm 1.094$ \\
\hline
\end{tabular}

We determined that our calculated value for $k_{p}$ above was sufficiently close that of Labotz, such that we could begin simulation of off-stoichiometry samples of $\mathrm{Mg}_{2} \mathrm{Si}$ and calculation of their respective values for $k_{p}$. 


\section{Results $-\mathrm{Mg}_{2} \mathrm{Si}$ with Si NPs}

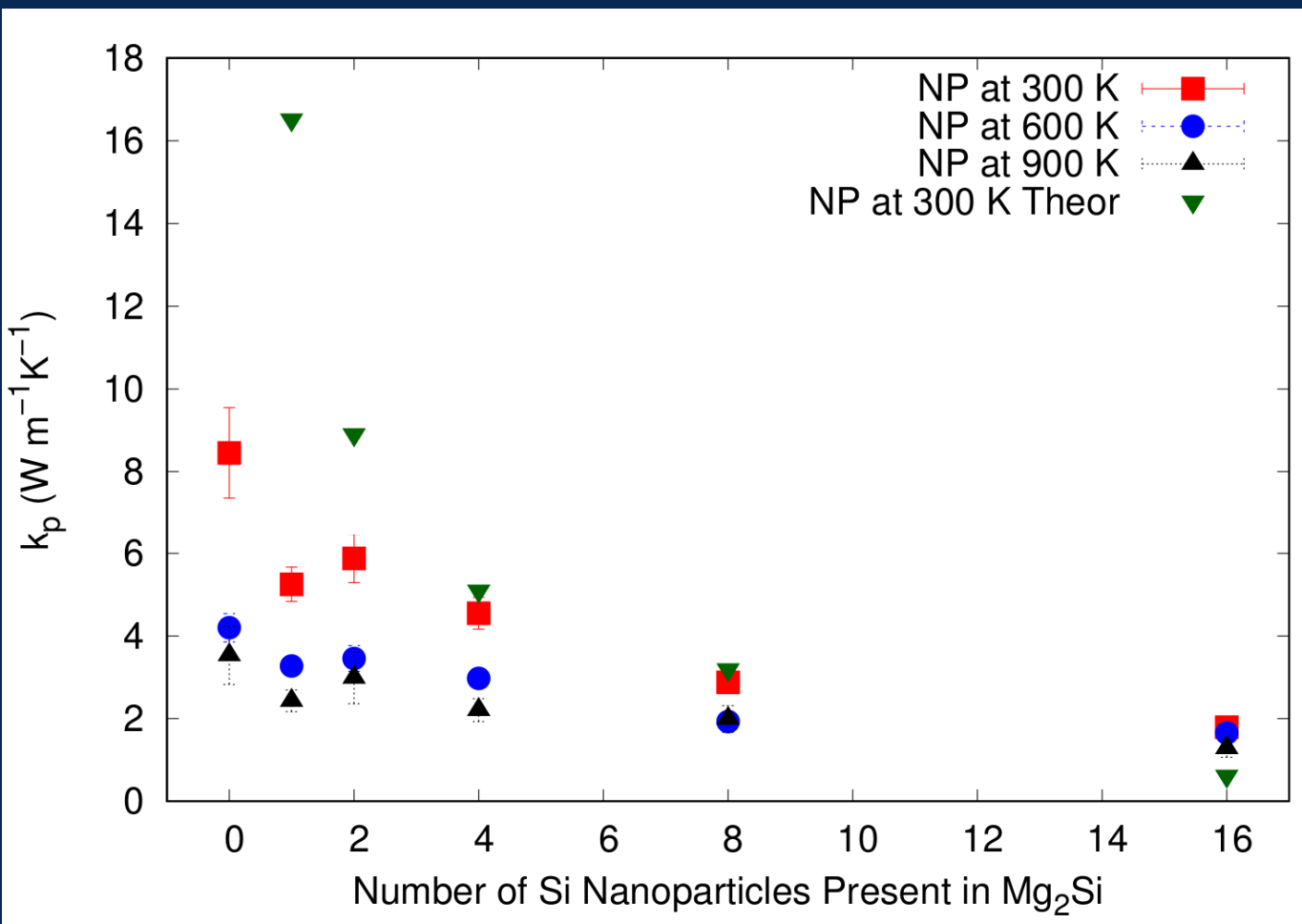

FIGURE 3: Lattice thermal conductivity $\left(k_{p}\right)$ vs. number of $\mathrm{Si} N P s$ present in $\mathrm{Mg}_{2} \mathrm{Si}$ samples at 300 , 600, and $900 \mathrm{~K}$. Included is an estimation of $k_{p}$ for the $300 \mathrm{~K}$ equilibration temperature case, using Eqn 4] [8], denoted by NP at $300 \mathrm{~K}$ Theor. 


\section{Results $-\mathrm{Mg}_{2} \mathrm{Si}$ with Si NPs}






\section{One Si NP Case}

- Unexpectedly, the 1 NP cases resulted in lower in $k_{p}$ values than their respective 2 NP cases

- We thought this might have to do with the NP spacing
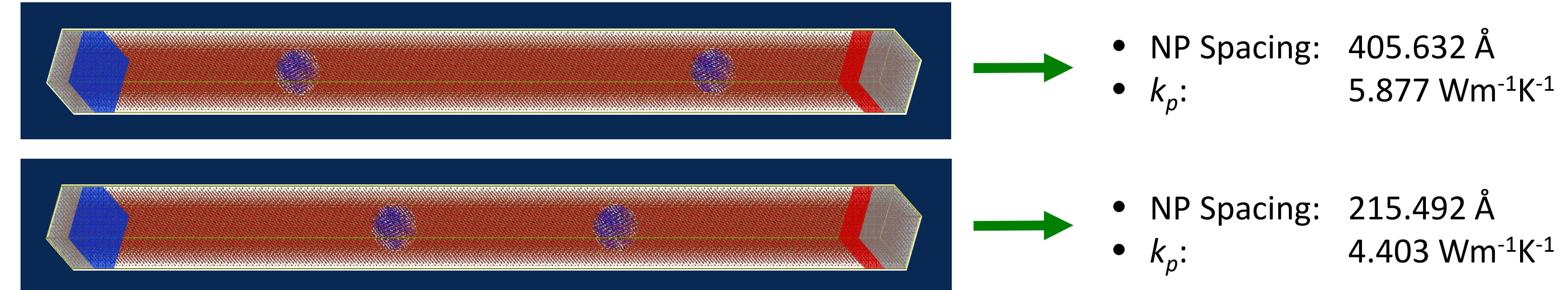

- NP Spacing: $215.492 \AA$

- $k_{p}$ : $\quad 4.403 \mathrm{Wm}^{-1} \mathrm{~K}^{-1}$

- It appears that the closer the Si NP concentration is to the center of the sample, the lower the $k_{p}$, despite no change in stoichiometry 


\section{Results $-\mathrm{Mg}_{2} \mathrm{Si}$ with Si Substitutionals}

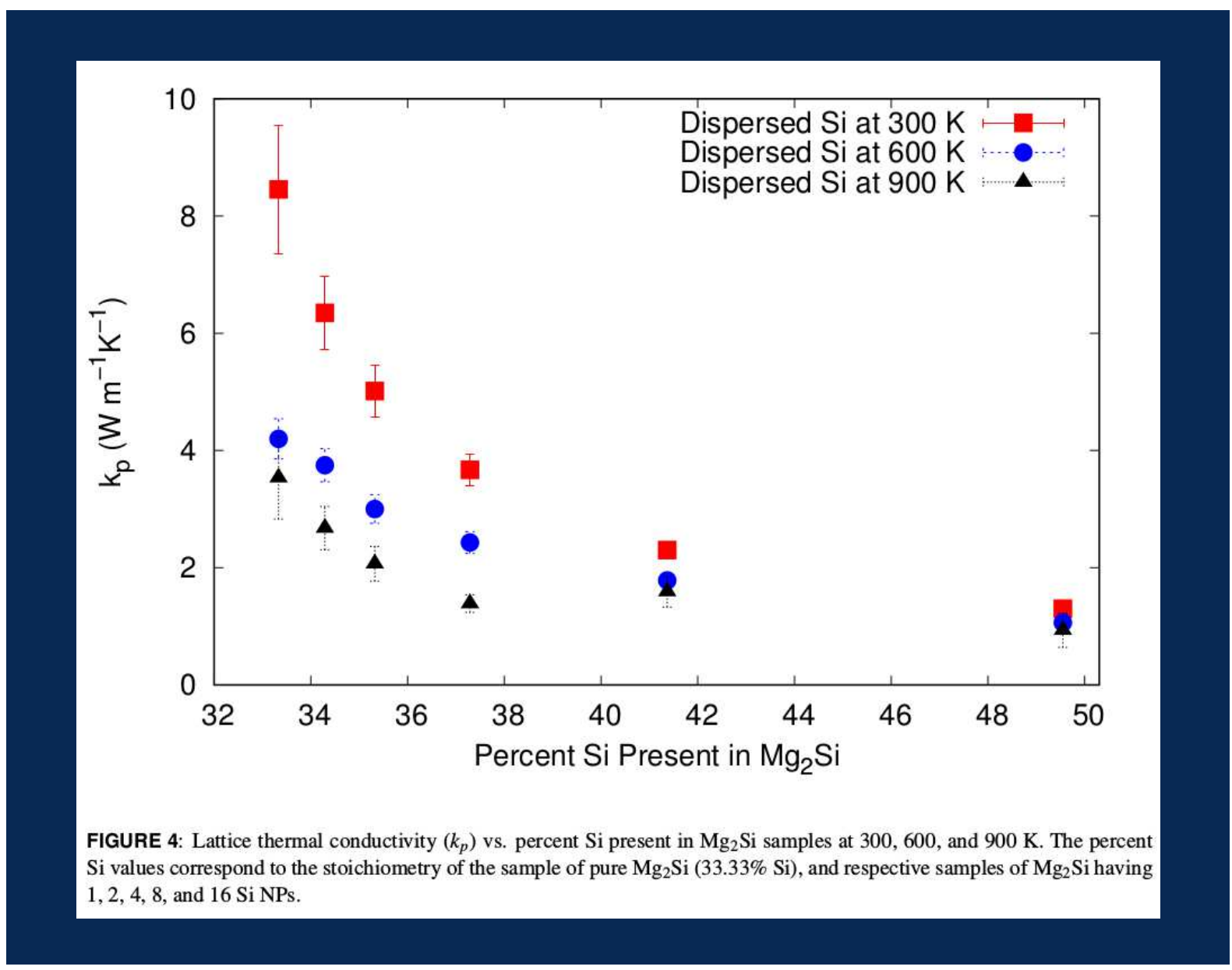




\section{Results $-\mathrm{Mg}_{2} \mathrm{Si}$ with Si Substitutionals}

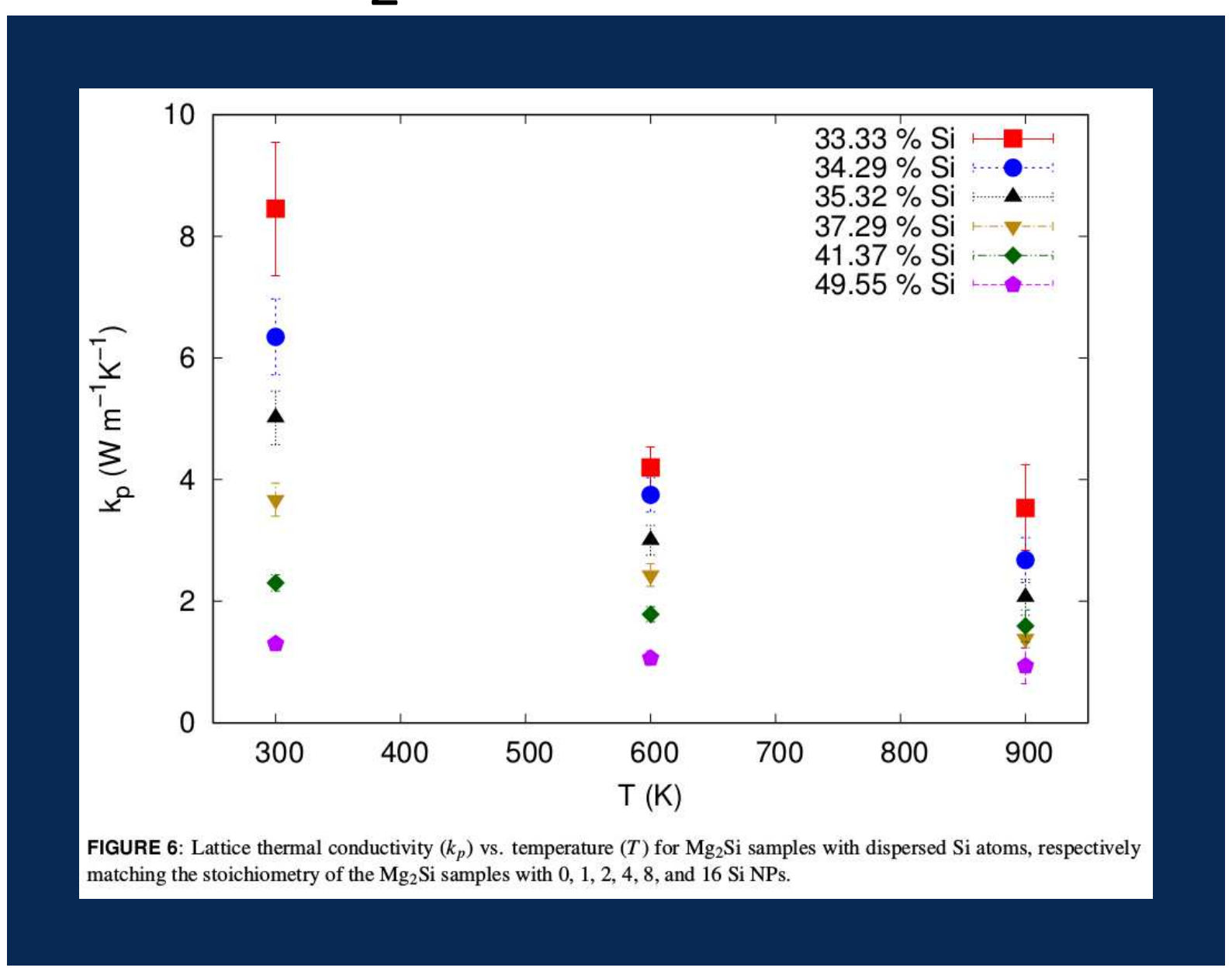




\section{Results - Table Summaries}

\begin{tabular}{|c|c|c|c|}
\hline Nanostructure & $300 \mathrm{~K}\left(\mathrm{Wm}^{-1} \mathrm{~K}^{-1}\right)$ & $600 \mathrm{~K}\left(\mathrm{Wm}^{-1} \mathrm{~K}^{-1}\right)$ & $900 \mathrm{~K}\left(\mathrm{Wm}^{-1} \mathrm{~K}^{-1}\right)$ \\
\hline Pure $\mathrm{Mg}_{2} \mathrm{Si}$ & $8.454 \pm 1.094$ & $4.199 \pm 0.342$ & $3.533 \pm 0.705$ \\
\hline $\mathrm{Mg}_{2} \mathrm{Si}$ with $1 \mathrm{Si} \mathrm{NP}$ & $5.252 \pm 0.416$ & $3.275 \pm 0.176$ & $2.428 \pm 0.261$ \\
\hline $\mathrm{Mg}_{2} \mathrm{Si}$ with $2 \mathrm{Si} \mathrm{NP}$ & $5.877 \pm 0.586$ & $3.456 \pm 0.312$ & $2.987 \pm 0.626$ \\
\hline $\mathrm{Mg}_{2} \mathrm{Si}$ with $4 \mathrm{Si} \mathrm{NP}$ & $4.553 \pm 0.387$ & $2.972 \pm 0.205$ & $2.204 \pm 0.277$ \\
\hline $\mathrm{Mg}_{2} \mathrm{Si}$ with $8 \mathrm{Si} \mathrm{NP}$ & $2.876 \pm 0.211$ & $1.930 \pm 0.119$ & $1.992 \pm 0.323$ \\
\hline $\mathrm{Mg}_{2} \mathrm{Si}$ with $16 \mathrm{Si} \mathrm{NP}$ & $1.791 \pm 0.124$ & $1.649 \pm 0.157$ & $1.280 \pm 0.214$ \\
\hline $\mathrm{Mg}_{x} \mathrm{Si}_{x} 34.29 \% \mathrm{Si}$ (matching stoichiometry of $\mathrm{Mg}_{2} \mathrm{Si}$ with $1 \mathrm{Si} \mathrm{NP}$ ) & $6.346 \pm 0.624$ & $3.749 \pm 0.283$ & $2.676 \pm 0.369$ \\
\hline $\mathrm{Mg}_{x} \mathrm{Si}_{x} 35.32 \% \mathrm{Si}$ (matching stoichiometry of $\mathrm{Mg}_{2} \mathrm{Si}$ with $1 \mathrm{Si} \mathrm{NP}$ ) & $5.015 \pm 0.441$ & $3.001 \pm 0.244$ & $2.065 \pm 0.296$ \\
\hline $\mathrm{Mg}_{x} \mathrm{Si}_{x} 37.29 \% \mathrm{Si}$ (matching stoichiometry of $\mathrm{Mg}_{2} \mathrm{Si}$ with $1 \mathrm{Si} \mathrm{NP}$ ) & $3.669 \pm 0.272$ & $2.430 \pm 0.186$ & $1.387 \pm 0.151$ \\
\hline $\mathrm{Mg}_{x} \mathrm{Si}_{x} 41.37 \% \mathrm{Si}$ (matching stoichiometry of $\mathrm{Mg}_{2} \mathrm{Si}$ with $1 \mathrm{Si} \mathrm{NP}$ ) & $2.300 \pm 0.133$ & $1.784 \pm 0.126$ & $1.591 \pm 0.264$ \\
\hline $\mathrm{Mg}_{x} \mathrm{Si}_{x} 49.55 \% \mathrm{Si}$ (matching stoichiometry of $\mathrm{Mg}_{2} \mathrm{Si}$ with $1 \mathrm{Si} \mathrm{NP}$ ) & $1.300 \pm 0.053$ & $1.064 \pm 0.117$ & $0.9347 \pm 0.292$ \\
\hline
\end{tabular}

畺离 $\frac{\text { COLLEGE of }}{\text { ENGINERING }}$ 


\section{Conclusions}

- Increasing the atomic percent $\mathrm{Si}$, either through substitutional atoms or Si NPs, decreases $k_{p}$

- Samples with substitutional $\mathrm{Si}$ atoms resulted in greater decreases in $k_{p}$ when compared to the $k_{p}$ of the samples with Si NPs

- Boundary resistance, rather than reduction in mean free path, seems have the greater influence in reducing $k_{p}$ in the samples with Si NPs for the 1 and 2 NP cases 


\section{Future Work}

- Experimental research will need to verify that these nanostructures actually result in an increased $Z T$ for $\mathrm{Mg}_{x} \mathrm{Si}_{x}$ as LAMMPS cannot account for changes in $k_{e}$

- Further work should be done to understand why substitutional $\mathrm{Si}$ atoms lower $k_{p}$ more than the stoichiometric equivalent of Si NPs in $\mathrm{Mg}_{2} \mathrm{Si}$

- Further should be done to understand more fully how concentrations of stoichiometric changes at certain locations, such as Si NPs at the halfway point between a heat source and sink, can change $k_{p}$ 


\section{References}

1. LaBotz, R. J., and Mason, D. R., 1963. "The thermal conductivities of mg2si and mg2ge". Journal of The Electrochemical Society, 110.2, pp. 121-126.

2. Plimpton, S. LAMMPS - large-scale atomic/molecular massively parallel simulator. http://lammps.sandia.gov/.

3. Rull-Bravo, Marta, et al. "Skutterudites as thermoelectric materials: revisited." Rsc Advances 5.52 (2015): 41653-41667.

4. Zhang, Hengji, e. a., 2015. "The effect of point defects and nanoparticles on thermal conductivity of magnesium silicide". Computational Materials Science, 104, pp. 172-176.

\section{Acknowledgements}

1. The Utah Energy Research Triangle Program from the Governor's Office of Energy

Development provided the funding for this project. 
Questions? 